\title{
Irreversible coma and withdrawal of life support: is it murder if the IV line is disconnected?
}

\author{
Bernard Towers University of California, Los Angeles, USA
}

A preliminary hearing has been set for December 3, I982, on a murder charge brought by the Los Angeles District Attorney ('public prosecutor') against two local physicians. ${ }^{*}$ At the end of August, 198I, they had withdrawn respirator-support from a 50-year-old surgical patient who had sustained severe brain damage during a cardiac arrest. This was in the recovery room following abdominal surgery for closure of an ileostomy. Brain-stem function had proved to be sufficiently intact to allow continuance of spontaneous breathing. The family, who had consented to withdrawal of life-supports, apparently requested transfer from the intensive care unit (ICU) to a private room, and subsequently (though the press accounts are confused on this point) demanded that all life-support systems be discontinued, including the intravenous line. The doctors removed the intravenous and nasogastric tubes, and ordered normal or 'ordinary' nursing care. Spontaneous breathing then continued for a week, and the autopsy findings included 'dehydration' as contributing to the demise. These facts will apparently be basic to the case for the prosecution.

An aspect of the American ethos, which is disturbing to one brought up with the English legal system, is the extent to which pre-trial publicity, via newspapers, radio and television, can prejudice readers, listeners, and viewers, to take positions pro or con long in advance of the hearing of evidence in court. In this instance a 'trial by media' began as long ago as May 30, with an article in a small local newspaper headlined 'Police Probe Hospital Patient's Slow Death'. A week later the prestigious Los Angeles Times carried a piece under the headline 'Grand Jury To Hear Testimony In Hospital Starvation Death Case'. Such inflammatory language, coupled with innuendos in the substance of the articles, represent some of the disturbing aspects of an aggressive society whose legal system is based on, and thrives on, adversarial confrontations at all stages of an enquiry. As soon as the fact of an official enquiry becomes public knowledge anyone with an axe to grind, or a need for publicity or for notice of some sort, is likely to get in on the act. Justice may eventually

\section{Key words}

Medical ethics and the law; euthanasia; ordinary and extraordinary means; life-support ethics. prevail, but the path is excessively tortuous, and often even torturous to those who are primarily involved.

Early in I98I a joint ad hoc committee on biomedical ethics of the Los Angeles County Medical Association (LACMA) and the Los Angeles County Bar Association (LACBA) developed, after six months' deliberation, a set of Guidelines for Discontinuance of Cardiopulmonary Life-support Systems under Specified Circumstances. They were adopted both by the council of LACMA and by the LACBA board of trustees, and were published in LACMA Physician on May 4, I98I. The Deputy District Attorney (DDA) then in charge of the medical-legal section of the District Attorney's (DA's) office had served on the joint committee. He said 'It is my opinion that a physician who follows the Guidelines is practising well within community standards and should therefore have no fear of any type of criminal prosecution'. However, it is not he, but his successor as head of the medical-legal section of the DA's office who will prosecute Drs Neil Leonard Barber and Robert Joseph Nejdl on a charge that they 'did wilfully and unlawfully and with malice aforethought, murder Clarence Leroy Herbert, a human being'. The former DDA is now a lawyer in private practice, and has been retained by the defence as one of their legal counsel.

The published Guidelines refer repeatedly to lifesupport systems in the plural, but mention only one in particular, namely the mechanical respirator or ventilator. They do not use the language of 'ordinary vs extraordinary means', nor do they attempt to define what constitutes normal, usual, customary or routine medical or nursing care under different sets of circumstances. One of the general principles listed is that 'the dignity of the individual must be preserved and necessary measures to assure comfort be maintained at all times'. Three sets of circumstances are listed 'in which decisions to discontinue the use of cardiopulmonary life-support systems can be made without the necessity of prior approval by the courts'. These are I) Brain Death, when certified according to California Law, ie, 'total and irreversible cessation of brain function' which is taken by most doctors to include, by inference, total cessation of brain-stem function; 2) California Natural Death Act, where a patient has previously signed a valid and binding 'Directive to Phys- 
icians' (I); and 3) Irreversible Coma. The Guidelines expressly state in a footnote that whereas the first two sets of circumstances 'are based on provisions of the California Health and Safety Code, this paragraph dealing with irreversible coma is not based on any California statute or court decision, but rather reflects our view of good medical practice and the current standard of medical care in Los Angeles County.' The case under review (if and when it comes to trial and judgment) will test the legal validity or wisdom of this section of the Guidelines. What is so distressing is that the trauma inevitably suffered in a California murder trial should have to be inflicted on so many people in order to test the validity of this third category, which states under Irreversible Coma:

'Cardiopulmonary life-support systems may be discontinued if all of the following conditions are present:

a. The medical record contains a written diagnosis of irreversible coma, confirmed by a physician who by training or experience is qualified to assist in making such decisions. The medical record must include adequate medical evidence to support the diagnosis;

b. The medical record indicates that there has been no expressed intention on the part of the patient that life-support systems be initiated or maintained in such circumstances; and

c. The medical record indicates that the patient's family, or guardian or conservator, concurs in the decision to discontinue such support.

The comfort and dignity of the patient shall be maintained if death does not occur on discontinuation of cardiopulmonary life-support systems.'

A Grand Jury hearing involves the giving of preliminary testimony to determine whether an indictment should be brought. The DA often uses it to obtain additional evidence. Six physicians from the hospital concerned (including one of those now charged) were subpoenaed. All six invoked the Fifth Amendment on legal counsel's advice, and refused to testify or to be questioned by the DDA. This generated more negative publicity, and for the first time a newspaper article on June 9 hinted at possible grounds for the 'malice aforethought' that the subsequent criminal charge would ultimately allege. Mr Herbert's treatment and death occurred in a hospital belonging to the KaiserPermanente system. This is the nation's largest prepaid health care system or 'health maintenance organisation' (HMO). Subscribers pay fixed monthly rates and are then entitled, at nominal additional cost, to total care at any of the system's hospitals - or elsewhere, by arrangement, if location or special needs necessitates the services of another hospital or other physicians. The system is rather like the National Health Service in Britain. Increasingly it is being regarded as a possible model for national health insurance, if that ever comes about in the United States (2). The Kaiser system, like other pre-paid HMO's, tends to be criticised for its shortcomings, and is generally disparaged by the 'private sector', that is by physicians in (largely) private hospitals. These latter operate strictly on a fee-for-service system. The fees are paid either by the patient (if very wealthy) or by private or: group insurance or - in the case of the elderly and thes? 'truly needy', and at rates and under conditions increase ingly determined by Washington - by the nationaE insurance system.

Kaiser physicians are particularly vulnerable tơ charges of penny-pinching in order to improve the economic efficiency of the system, since this would ${ }^{\$}$ ultimately redound to their own financial advantage $\vec{O}$ the way the system is set up the physicians form a professional 'group' (numbering some I,700 in the Los Angeles area) which enjoys an exclusive contract to provide care for patients at the (six) Kaiser hospitals ind the region. A portion of their income may depend on the financial success of the system.

It has been this correspondent's experience, during many Kaiser seminars on ethical and legal problems in medicine, that their physicians are acutely aware of their vulnerability to charges of wanting to provide less or cheaper 'care' than might be provided in the more strictly private sector. On one occasion, during discus $-\frac{\mathbb{}}{3}$ sion of what ought to be done for a respirator: dependent infant who had a hopeless prognosis but whose mother could not accept the inevitable outcomeso and continued to insist that 'everything be done' suggested that they could always go to court for permission to withdraw the life-support systems. This regrettable but sometimes (and increasingly) necessary manoeuvre if one is to provide what is best and mosø appropriate for a dying patient. The Kaiser physicianso asked me to imagine what kind of an outcry might develop in newspapers and magazines, and on radiog and television. I had to agree that in this scandal- $\frac{-}{5}$ hungry society my suggested course of action would be unwise, despite its professional (both medical and legal) correctness.

But now two Kaiser doctors stand charged with ${ }^{\overparen{\Phi}}$ murder because they acted with what they have stated was compassionate concern for a patient's best interesto and that of his family. They did not do what hospitaf administrators increasingly advise or require should be done, and what a neurology consultant on this casespecifically suggested, namely, seek legal advice $\frac{D}{0}$ before withdrawing respirator-support, from the hospital's counsel. The clinical decisions were made by ô clinicians literally 'at the bedside'. That is where many think they should be made, rather than in a lawyer's office or a court-room. In addition, doctors do not take kindly, on the whole, to advice or directions from $a 2$ member of the nursing staff. It was one of the nurseso who objected to the management of Mr Herbert's irreversible coma. She promptly resigned from the hospital and subsequently delated the doctors and the hospital to all the agencies who might have an interesto in investigating her allegations. Her name and some of her opinions surfaced in the press during the spate ofo media coverage following the official filing of charges? 
on August 18 and the formal arraignment on September I4. With each step in the case to date, the media coverage has become more intense. During the August flurry of activity the DDA was everywhere to be seen and heard and read about. He must have devoted many hours to being in front of news cameras, microphones and tape-recorders. The doctors themselves stayed pretty quiet, although their attorneys made some pungent observations to TV and press. It would have been possible to apply for a court restraining order on further publicity while the case is sub judice. This, however, is a two-edged sword in a society where 'freedom of the press' and 'the right to know' are slogans that suggest that if you aren't prepared to 'let it all hang out' you must be hiding something that is either illegal or shameful. When a prosecutor has acted so zealously in the media in pursuit of his goals, at a time more than three months before even a preliminary court hearing (set for December 3), it is not surprising that the accused should want to make some kind of rejoinder. So eventually, in September, we saw and heard from Drs Barber and Nejdl, quietly stating that they had indeed followed the Guidelines approved last year, and that they were motivated throughout by compassionate concern for the late $\mathrm{Mr}$ Herbert and for members of his family.

It might be helpful if, prior to the trial, some clarification could be made as to what does constitute appropriate clinical care (both medical and nursing care) for the dying patient who is comatose. Coma comes to virtually (perhaps absolutely) everyone for a variable period of time before death. Being in a coma means being unconscious; in deep coma, as Mr Herbert was, means deeply unconscious and unresponsive to all stimuli; if the condition is in fact permanent and irreversible, and if postmortem examination of the brain shows that that clinical judgment was correct then what would be, or what would have been, appropriate clinical care? What does it mean to maintain or promote the 'comfort and dignity' of the dying patient? When a patient is conscious to even the smallest degree, and if he appears to be thirsty and to have a swallowing reflex, and if there is no contraindication to oral fluids, his comfort and dignity would surely demand that he be given nourishing liquids, or at least water. If he lapses into coma, good nursing practice has traditionally required sponging out the mouth and moistening the lips. Now, if he lapses into deep coma and is on a dying trajectory, would we then try to 'push' fluids by mouth or nasogastric tube? If we did, dignity would surely suffer. The 'comfort' of the patient would, of course, be unaffected if the coma were deep enough and irreversible.

Why should it be thought to be different just because it is so easy to set up an intravenous drip rather than use the more difficult, but more natural, gastro-intestinal route? The routine use of IV drips has brought many benefits. But it also carries inconveniences and risks to the patient, all of which should be measured against the convenience to the staff of having a ready route of access for the administration of whatever it is thought good to instill into the patient's body. Perhaps in some circumstances the only major benefit afforded by the IV drip is to the medical and nursing staff, since it gives them the emotional satisfaction and comfort of thinking that at least something is being done.

The presence of an IV demands careful attention to fluid input and output, and daily or more frequent analysis of blood chemistry to check the effects on the body's homeostatic mechanisms. These measures can sometimes go very wrong in the terminal stages. Or they can go apparently 'right', although the patient dies: we are familiar with the pleased but slightly puzzled look of the resident who announces that the blood electrolytes were in balance just so many hours or minutes before death! If the patient had been dying in irreversible coma, for whose benefit and in whose interest were all those tests, all that activity performed?

When things go wrong with IV fluids they can be disastrous. My old colleague in Pathology in Cambridge (the 'University Morbid Anatomist', as he is officially titled) used to make a point of demonstrating, at autopsy, the extent and degree to which 'waterlogging' of the corpse's tissues had sometimes occurred. 'You drowned this patient', he would declare to the assembled clinicians. On the wall of that autopsy room was a saying attributed to Napoleon, 'I do nof want to have two diseases, one nature-made and one doctor-made'. Sometimes it is better to leave things to nature, especially when a patient is dying.

When this case comes to trial - it still might not, of course, but it would be a bold and maybe foolish judge who would, at this stage and in view of the considerable public interest, refuse permission for the prosecution to proceed - it may be that what will really be tried are, first the published Guidelines for the withdrawal of life-support systems, and second the practice of routine administration of intravenous fluids. If withdrawal of IV fluids from a deeply comatose patient is considered equivalent to denying food and water to a conscious patient and thereby 'starving him to death' (as some of the media stories in this instance have suggested) then we might as well be with Alice in Wonderland, playing crazy croquet with the red queen.

*The reader should know and bear in mind that on $f$ une 30 the writer was asked by the hospital's attorneys to review and report on the patient's chart. He may be called to testify for the defence at the trial.

\section{References}

(I) Towers B. Report from America. Fournal of medical ethics $1978 ; 4: 96-98$.

(2) Towers B. Report from America. Fournal of medical ethics $1977 ; 3: 42-48$. 